\title{
Effectiveness of Diabetic Education Programme on the HbA1c Levels Among Type1 Diabetic Children in Omdurman Paediatric Hospital
}

\author{
Rabia Ali E. Babikeir ${ }^{1}$, Mohamed O. Elsamani ${ }^{2, ~ ", ~ O m a r ~ Y o u s o f ~ M . ~ A l i ~}{ }^{3}$, \\ Azhari A. Mohammed Nour ${ }^{2}$ \\ ${ }^{1}$ Department of Nursing Science Faculty of Applied Medical Sciences Al-Taif, Saudi Arabia \\ ${ }^{2}$ Department of Basic Medical Sciences Faculty of Applied Medical Sciences Al-BAHA Saudi Arabia \\ ${ }^{3}$ Department of Community Health Faculty of Applied Medical Sciences Al-BAHA, Saudi Arabia
}

Email address:

mhmdomer6@gmail.com (M. O. Elsamani)

${ }^{*}$ Corresponding author

To cite this article:

Rabia Ali E. Babikeir, Mohamed O. Elsamani, Omar Yousof M. Ali, Azhari A. Mohammed Nour. Effectiveness of Diabetic Education Programme on the HbA1c Levels Among Type1 Diabetic Children in Omdurman Paediatric Hospital. Advances in Applied Sciences. Vol. 2, No. 1, 2017, pp. 1-6. doi: 10.11648/j.aas.20170201.11

Received: September 6, 2016; Accepted: November 4, 2016; Published: December 2, 2016

\begin{abstract}
Education of patients with diabetes is considered a fundamental aspect of diabetes care and aimed to evaluate the effectiveness of diabetic education, using a guiding style, for children with Type 1 diabetes in Omdurman pediatric hospital. The aim of this study was to achieving a near normal glycosylated hemoglobin, and preventing acute complications (hypoglycemia, hyperglycemia) on the children patients with typel diabetic in Khartoum state. The sampling size was (101) according to the attendance to Diabetic clinic during data collection period (February - August 2013) in this study, the Control of diabetes through HA1C monitoring was measured prior to the intervention and over seven months after post-test. The result of present study showed that: the effective method of diabetes education for children with type1 diabetes has improved such as HA1C was significantly reduced from $11.6 \%$ to a mean of $9.1 \%$.glycaemic control. Innovative education programme for Diabetic children with type 1 diabetes. It is effective in reducing the diabetes complications among diabetic children such as hyperglycaemia and hypoglycaemia. This educational programme for diabetic children is effective in reducing HA1c after seven months intervention. Diabetic educational program administered to type1 diabetes mellitus patients seen at a Diabetic clinic improved the knowledge and distress associated with the disease. The results also suggest the prevention of an increase in $\mathrm{HbA1c}$.
\end{abstract}

Keywords: Diabetes Mellitus, Glycemic Control, Children, HbA1c, Patients

\section{Introduction}

Diabetes is a chronic and progressive disorder that has an impact on almost every aspect of life. The number of people with diabetes mellitus is expected to increase worldwide from 175 million in 2000 to 353 million in 2030. Diabetes Mellitus in children is a chronic medical problem, with many complications affecting the Growth and Development in early and late childhood. Children are now developing type 1 diabetes at an earlier age. The overall incidence of type 1 diabetes in 2010 is predicted to be approximately 40\% higher than the incidence recorded in 1997 [1]. Evidence has been accumulating that demonstrates a worldwide increase in the incidence of type 1 diabetes mellitus, with incidence rising especially in areas where type 1 diabetes was previously low [2]. Thirteen million people in the United State are diagnosed with diabetes type 1 diabetes is diagnosed in approximately 1 of every 400 to 500 children and adolescents. The median age of onset is between 7 and 15 years [3]. The classic initial symptoms of hyperglycemia, known as "the three $\mathrm{P}$ " are polyuria, polydipsia, and polyphagia. The child symptoms also include weight loss, fatigue, and blurred vision. [4] Diagnosis of type 1 diabetes mellitus is made on basis of a clinical picture of hyperglycemia combined with laboratory 
data of fasting serum glucose exceeding $126 \mathrm{mg}$-dl and random serum glucose of $200 \mathrm{mg}$-dl. According to the American Diabetes Association (ADA) [10]. A1C reflects the average blood glucose over several months and has a strong predictive value for diabetes complications. I intend on helping the patients in our practice achieve improved glycemic control to minimize the risk of associated complications. Housden, Wong, \& Dawes [11] report for every 1 percent reduction in a $\mathrm{HbAlc}$, there is a $37 \%$ decrease in micro vascular complications. The risk of developing eye, kidney, and nerve disease is reduced by 40 percent with a decrease in HbA1c. Schaffer [12] reports a middle-aged U.S. adult with diabetes will develop a disability six to seven years earlier than an adult without diabetes and spend more years in a disabled stated. There are two studies studied the effects on glycaemic control of the most commonly used insulin and the relations between glycaemic control and diabetic complications. When relating $\mathrm{HbA1c}$ to diabetic complications we introduced the term HbAlc-variable describing different weightings and combinations of $\mathrm{HbAlc}$ values. In a systematic review we found that the baseline value was most common to use in studies of $\mathrm{HbAlc}$ and diabetic complications, but a mean value of many $\mathrm{HbA} 1 \mathrm{c}$ values had greater predictive ability [9].

\section{Material and Methods}

\subsection{Patients}

Subjects were eligible to participate in the trial if they met the following inclusion criteria: a young subjects (between 6 and 18 years), with type 1 diabetes mellitus and $\mathrm{HbA} 1 \mathrm{c}>11 \%$, attending the Omdurman pediatric hospital Diabetic clinic. The sampling size was (101) according to the attendance to Diabetic clinic during data collection period from February to August 2013.

\subsection{Research Design}

Interventional study, as pre and post intervention design, this study implemented, and evaluated diabetic education programme of diabetic children for controlling the blood sugar. The researchers first, assessed the situation in the study area; followed by modification and preparation of the educational programme, then, raising knowledge and skills of diabetic children and their carers for controlling blood sugar. Finally, evaluation of the impact of the diabetic educational on children with typeldiabetes and HbAlc levels and occurrence of diabetes complications was conducted.

\subsection{Data Analysis}

The data was analysed by using Statistical Package for Social Sciences (SPSS) version 20 for quantitative data to find out HbAlc- mothers' knowledge and practice. Total score of knowledge and behaviour were also calculated, from scores of each questions provided, and compared at pre-test and post-test. The significant differences at $95 \%$ confidence interval level was used due which were measured by paired sample $t$ test, which usually used to measure the difference in one group at different times such as pre and post intervention scores.

\section{Results and Discussions}

The samples size consists of 101 diabetic children as a total coverage. The Statistical Package for Social Science (SPSS) version 20 was used to analyse the quantitative data and statistical significance was set at alpha 0.05 using paired sample t-test. The results include frequencies and percentages then followed by descriptive statistics for diabetic patients' knowledge and skills. Non-parametric chi square and independent t-test was used to examine the difference before and after interventions to compare the effect of influencing factors.

Table 1. Difference in knowledge of target group about diabetes at pre and post intervention in Omdurman Paediatric Hospital, $n=101$.

\begin{tabular}{|c|c|c|c|c|c|c|}
\hline \multirow{2}{*}{ No. } & \multirow{2}{*}{ Item } & \multicolumn{2}{|c|}{ Correct answer Before intervention } & \multicolumn{2}{|c|}{ Correct answer After intervention } & \multirow{2}{*}{ p-value } \\
\hline & & Freq. & $\%$ & Freq. & $\%$ & \\
\hline 1 & Respondents know what the diabetes & 24 & 23.8 & 98 & 97.0 & 0.01 \\
\hline 2 & Respondents know the management & 9 & 8.9 & 101 & 100.0 & 0.00 \\
\hline 3 & Components of management & 81 & 80.2 & 57 & 56.4 & 0.23 \\
\hline 4 & Respondents know what the symptoms of hypoglycemia & 21 & 20.8 & 100 & 99.0 & 0.00 \\
\hline 5 & Symptoms of hypoglycemia & 47 & 46.5 & 100 & 99.0 & 0.05 \\
\hline 6 & Respondents know the symptoms of hyperglycemia & 25 & 24.8 & 97 & 96.0 & 0.03 \\
\hline \multicolumn{2}{|c|}{ Total knowledge about diabetes } & $34.8 \%$ & & $88.5 \%$ & & 0.01 \\
\hline
\end{tabular}

This table reflects the significant differences of detailed knowledge about diabetes before and after intervention. The results show that; participants who participated in the study have highly significant scores of knowledge at post-test than the scores at pre-test. That means the intervention increases the level of knowledge significantly except for the components of management which is not significant. The table also reflects the total knowledge increased after intervention from $34.8 \%$ to $88.5 \%$, the total knowledge has been calculated using liker scale described in questionnaire since each correct response scored one and then per cent of overall correct was calculated. Data from post-test were analysed using analysis of paired sample t-test, usable for pre-post comparison, to compare score of knowledge between pre-intervention and post-intervention. It was also used to compare score of skills between pre-test and post-test and to address hypothesis of the study. The effects of diabetic children intervention programme have a significant role in 
the reduction of diabetes complications occurrence. When evaluating glycaemic control in clinical practice the laboratory marker glycated haemoglobin (HbAlc) is the golden standard [7]. The present study revealed that the value of HA1c (at pre-test) and then (at post-test). HA1c was decreased from 11.6 to 9.1 due to diabetic children care training for seven months. The difference at pre-test and post-test is statistically highly significant; $p$-value is less than 0.00 , this finding supports the hypothesis. The study showed that there is no relationship between the HbAlc and the diabetes complication. This study is contradicting several epidemiologic studies on relations between higher $\mathrm{HbA1c}$ levels and diabetes complications which reflected the poor diabetes control [8] Another study on effects of a structured educational intervention on metabolic control of type-1 diabetes mellitus patients was found that; the mean $\mathrm{HbAlc}$ level in the 21 children and adolescents at initial, 3rd and 6th month were $10.05 \%$ (SD 2.67\%), $10.28 \%$ SD $2.23 \%$ ) and $10.01 \%$ (SD 2.67\%), which showed no significant changes $(\mathrm{P}>0.05)$. After 6 educational sessions, the result showed significant changes in both parents' $(\mathrm{P}<0.05)$. [5] This study reflects significant reduction of HA1 $\mathrm{c}$ after intervention which conform with results from a Long-term effects of a structured intensive diabetes education programme (SIDEP) in patients with Type 1 diabetes mellitus-a 4years follow-up study, it was found that; The mean HbAlc of the SIDEP group was significantly lower than that of the control group at 6 months, and at 3 and 4 years $(P<0.05)$. In particular, the mean HbA1c dropped dramatically after 6 months in the SIDEP group. At 4 years, the HbAlc was 1.5 and $0.5 \%$ lower than at baseline in the SIDEP and control groups, respectively (SIDEP vs. control, $7.9 \pm 1.2$ vs. $8.7 \pm 1.6$, respectively; $(\mathrm{P}<0.05)$. [6]

Table 2. Admission rate of diabetic children to hospitals at pre and post intervention due to hypoglycaemia and hyperglycaemia in Omdurman Paediatric Hospital, $n=101$.

\begin{tabular}{llllll}
\hline \multirow{2}{*}{ Admission } & \multicolumn{2}{l}{$\begin{array}{l}\text { Admission } \\
\text { Before intervention }\end{array}$} & \multicolumn{2}{l}{$\begin{array}{l}\text { Admission } \\
\text { After intervention }\end{array}$} & \multirow{2}{*}{ p-value } \\
\cline { 2 - 5 } & freq. & $\mathbf{\%}$ & freq. & $\mathbf{\%}$ & \\
\hline Admission during last 2 weeks by hypoglycemia & $45 / 101$ & 44.6 & $16 / 101$ & 15.8 & 0.02 \\
Admission during last 2 weeks by hyperglycemia & $79 / 101$ & 78.2 & $10 / 101$ & 9.9 & 0.01 \\
\hline
\end{tabular}

Chi square equal 4.53 .

This table reflects that; diabetic children health education programme reduce the admission due to diabetes complication. It reduces admission of hypoglycaemia from $44.6 \%$ to $15.8 \%$ and admission due to hyperglycaemia from $78.2 \%$ to $9.9 \%$. The reduction of both complications is statistically significant.

Table 3. Difference in mean of HbAlc between pre-test and post-test in Omdurman Paediatric Hospital

\begin{tabular}{llll}
\hline Mean of HbA1c of diabetic patients & Pre-test & 11.6 & 0.00 \\
\hline
\end{tabular}

However the significant reduction in mean of HA1c to $9.1 \%$, the level is still high. Long term intervention rather than seven months may result in reducing the HAlc to normal range.

This table and figure reflect the differences in total score of HbA1c at pre and post-test. The results show that; participants who participated in the study have low value of HbAlc (9.1) at post-intervention than the score at pre-test (11.6). That means the intervention decreases the level of HA1c in diabetic children. Figure $1: \mathrm{HbA}_{1} \mathrm{c}$ for all children

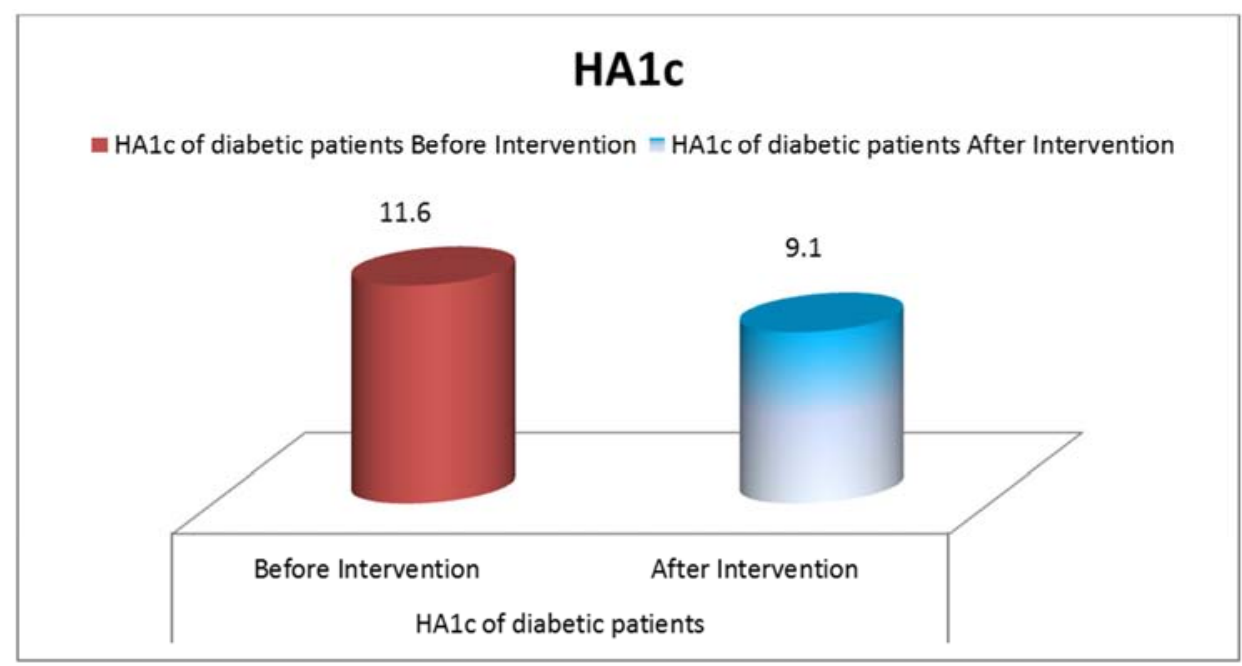

Figure 1. Difference in mean of HbAlc between pre-test and post-test in Omdurman Paediatric Hospital. 
Rabia Ali E. Babikeir et al:: Effectiveness of Diabetic Education Programme on the HbA1c Levels Among

Type1 Diabetic Children in Omdurman Paediatric Hospital

Table 4. The HbAlc for all children before and after intervention.

\begin{tabular}{|c|c|c|}
\hline No. & Hb A1 c before & Hb A1 c after \\
\hline 1. & 12 & 6.9 \\
\hline 2. & 10.2 & 9.2 \\
\hline 3. & 10.8 & 7.9 \\
\hline 4. & 11 & 6.8 \\
\hline 5. & 14 & 13 \\
\hline 6. & 11.5 & 7.5 \\
\hline 7. & 12.2 & 11.2 \\
\hline 8. & 10.5 & 8.1 \\
\hline 9. & 10.5 & 8.5 \\
\hline 10. & 11 & 10 \\
\hline 11. & 11.9 & 10.8 \\
\hline 12. & 11.3 & 9.5 \\
\hline 13. & 11 & 8 \\
\hline 14. & 12.2 & 10.2 \\
\hline 15. & 12 & 9.3 \\
\hline 16. & 10.4 & 9.4 \\
\hline 17. & 11 & 9.5 \\
\hline 18. & 12 & 9.9 \\
\hline 19. & 11 & 10.4 \\
\hline 20. & 11 & 8.3 \\
\hline 21. & 10 & 7.2 \\
\hline 22. & 12.1 & 11.1 \\
\hline 23. & 12.4 & 11.1 \\
\hline 24. & 11.3 & 10 \\
\hline 25. & 12.3 & 10.7 \\
\hline 26. & 11.6 & 10.5 \\
\hline 27. & 10.3 & 5.6 \\
\hline 28. & 11.8 & 6.4 \\
\hline 29. & 10.5 & 9.9 \\
\hline 30. & 13 & 12.6 \\
\hline 31. & 12 & 11 \\
\hline 32. & 10.1 & 8.9 \\
\hline 33. & 12 & 11.1 \\
\hline 34. & 11 & 9 \\
\hline 35 . & 11.3 & 10 \\
\hline 36. & 11 & 7.9 \\
\hline 37. & 11 & 8.4 \\
\hline 38. & 12 & 9 \\
\hline 39. & 10 & 10 \\
\hline 40. & 11 & 9 \\
\hline 41. & 12 & 9.3 \\
\hline 42. & 10 & 8.5 \\
\hline 43. & 12 & 8.5 \\
\hline 44. & 11 & 8.5 \\
\hline 45. & 12 & 9 \\
\hline 46. & 11 & 8 \\
\hline 47. & 12 & 8.8 \\
\hline 48. & 12 & 8.4 \\
\hline 49. & 11.7 & 8.5 \\
\hline 50. & 10.9 & 8.5 \\
\hline 51. & 11 & 6.9 \\
\hline 52. & 10 & 7.9 \\
\hline 53. & 14 & 13 \\
\hline 54. & 11 & 8.5 \\
\hline 55. & 12 & 9.5 \\
\hline 56. & 12.2 & 11.2 \\
\hline 57. & 11.6 & 9.9 \\
\hline 58. & 7.2 & 7.2 \\
\hline 59. & 11.1 & 11.1 \\
\hline 60. & 11 & 10 \\
\hline 61. & 12 & 5.6 \\
\hline 62. & 13.4 & 12.6 \\
\hline 63. & 13 & 8.9 \\
\hline 64. & 11 & 7.9 \\
\hline
\end{tabular}




\begin{tabular}{|c|c|c|}
\hline No. & Hb A1 c before & Hb A1 c after \\
\hline 65. & 12 & 9 \\
\hline 66. & 11 & 8.5 \\
\hline 67. & 12.8 & 8.5 \\
\hline 68. & 12 & 8.4 \\
\hline 69. & 12.6 & 10.4 \\
\hline 70. & 12 & 6.9 \\
\hline 71. & 12 & 7.9 \\
\hline 72. & 14 & 13 \\
\hline 73. & 10.5 & 8.5 \\
\hline 74. & 12 & 9.5 \\
\hline 75. & 12.2 & 10.2 \\
\hline 76. & 12 & 9.9 \\
\hline 77. & 13 & 7.2 \\
\hline 78. & 11.1 & 11.1 \\
\hline 79. & 13.8 & 8.6 \\
\hline 80. & 12 & 6.6 \\
\hline 81. & 12.6 & 11 \\
\hline 82. & 12 & 8.9 \\
\hline 83. & 12 & 7.9 \\
\hline 84. & 11 & 9 \\
\hline 85. & 12.5 & 8.5 \\
\hline 86. & 12 & 8.5 \\
\hline 87. & 12 & 8.4 \\
\hline 88. & 11 & 8.9 \\
\hline 89. & 11 & 5.6 \\
\hline 90. & 13.4 & 8.9 \\
\hline 91. & 11.6 & 9 \\
\hline 92. & 12 & 8.5 \\
\hline 93. & 10.5 & 8.5 \\
\hline 94. & 10.9 & 8.9 \\
\hline 95. & 11.5 & 6.8 \\
\hline 96. & 12.6 & 10 \\
\hline 97. & 12.4 & 10 \\
\hline 98. & 11 & 9.4 \\
\hline 99. & 12 & 8.8 \\
\hline 100. & 12 & 10 \\
\hline 101. & 11.7 & 10 \\
\hline Mean & 11.6 & 9.1 \\
\hline
\end{tabular}

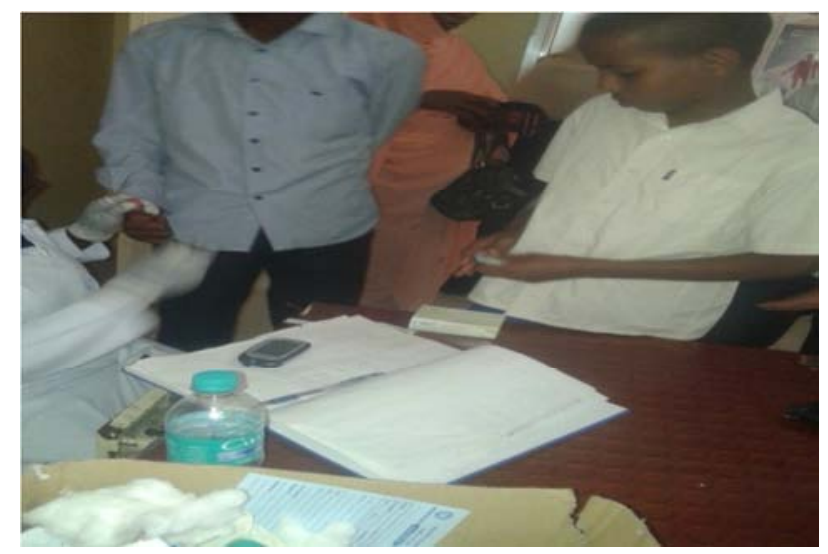

Figure 2. Blood glucose and HbAlc monitoring for participated children.

\section{Conclusions}

The educational programme for diabetic children was very clear that; is a useful tool to improve knowledge and distress related to diabetes, as well as to prevent progressive increases in HbAlc in typel diabetes mellitus patients attending a diabetic clinic. Also this programme was effective in reducing the diabetes complications among diabetic children such as hyperglycaemia and hypoglycaemia.

\section{Acknowledgments}

The authors wish to thank the patients, their families and Diabetic clinic, Omdurman pediatric hospital in Khartoum state Sudan, for their support during this research.

\section{References}

[1] Lever M. R. M. (2006) Pediatrics and child health, second edition $\mathrm{p}$ (295), 2006.

[2] James. S. R. (2007). Nursing care of children: Principles of practice, third edition, 2007.

[3] Elbagir M, Eltom MA. A (1989). population-based study on prevalence of diabetes in northern Sudan Diabetes Care; 24: $1126-8,1996$

[4] American Diabetes Association: Insulin and other drugs. Accessed on 12/01/2012 on http://www.diabetes.org/type-1diabetes/injections.jsps 
[5] Bernie E, Jose RL, and Boediman I., (2006). Effects of a structured educational intervention on metabolic control of type-1 diabetes mellitus patients, Pediatric an Indonesian, 2006.

[6] Ahn Y. B., (2006). Long-term effects of a structured intensive diabetes education programme (SIDEP) in patients with Type 2 diabetes mellitus - a 4-year follow-up study. Diabetic MedicineJournal, Seoul, South Korea, 2006.

[7] Jeffcoate SL. (2004). Diabetes control and complications: the role of glycated hemoglobin, 25 years on. Diabetic Medicine.21:657-665; 2004.

[8] McCance DR, Hadden DR, Atkinson AB, rcher DB et al. (1989). Long-term glycaemic control and diabetic retinopathy. Lancet. 2:824-828; 1989.
[9] Lind M. (2009). Glycaemic control: evaluations of HbAlc as a risk factor and the effects of modern insulin in clinical practice. University of Gothenburg, Sweden; 2009.

[10] American Diabetes Association. (2016, January). Glycemic Targets: Assessment of Glycemic Control. Diabetes Care, 39, 33-40. Retrieved from

http://care.diabetesjournals.org/site/misc/2016-Standards-ofCare.pdf.

[11] Housden, L., Wong, S. T., \& Dawes, M. (2013, September 27). Effectiveness of group medical visits for improving diabetes care: A systematic review and meta-analysis. Canadian Medical Association Journal, 185(13). Retrieved fromhttp://www.ncbi.nlm.nih.gov/pmc/articles/PMC3778483

[12] Schaffer, R. (2016, February). Diabetes reduces disability-free life-years, increases mortality. Endocrine Today, 14(2), 34-35. 